\title{
LA SEMIÓTICA EN URUGUAY
}

\author{
Marisol Álvarez \\ (con la colaboración de Richard Danta)
}

Universidad Católica del Uruguay

\section{INTRODUCCIÓN}

Desde los primeros trabajos definidos por la perspectiva semiológica europea de corte estructuralista y postestructuralista, a las actuales miradas que privilegian la lógica-semiótica del norteamericano Charles S. Peirce, la producción semiótica en Uruguay ha recorrido un camino muy parecido al de la propia historia de la disciplina en Occidente.

El relevamiento de las distintas publicaciones evidencia un corpus ecléctico que se inicia en los años ochenta con el análisis casi hegemónico de los lenguajes naturales y la literatura, y llega a finales de este siglo privilegiando los cuerpos, las pasiones y las razones presentes en dos lugares de sentido fundamentales a la cultura uruguaya: la televisión y la vida cotidiana. 
Con el propósito de consignar la historia de la producción semiótica en Uruguay, este trabajo presenta las principales tendencias teóricas que le han dado marco, el tipo de objetos que han sido privilegiados por el análisis y finalmente, el conjunto de publicaciones que pueden considerarse como representativas del trabajo semiótico en el país.

\section{EL ENFOQUE ESTRUCTURALISTA Y POSTESTRUCTURALISTA: LITERATURA, TEATRO Y CINE}

Anteriormente a una circulación de conocimiento que se legitimaría a partir de los ochenta, la producción semiótica uruguaya tuvo antecedentes individuales de orientación estructuralista en publicaciones aisladas de temas tan variados como la consideración del lenguaje publicitario (Block de Behar, 1973), la discusión de la obra de Saussure (Tani, 1979), los alcances cinematográficos y verbales del modelo comunicacional de Jakobson (Block de Behar, 1980), las poéticas literarias (Tani, 1984) y el lugar del silencio y el lector en los discursos literarios (Block de Behar, 1984).

La sistematización de la producción semiótica en Uruguay comenzó a partir de 1985 con la aparición de la revista Relaciones, una publicación independiente y de circulación alternativa al aparato académico institucional, que integraba en su staff de colaboradores a docentes universitarios interesados en la producción de conocimiento en un marco transdisciplinario.

El subtítulo de la revista era Al tema del hombre. Antropología, comunicación, ética, lingüística, psicoanálisis, psiquiatría, sociología, lo que implicó que, entre líneas teóricas y problemas específicos de diferentes disciplinas, la aparición de los primeros trabajos relacionados con semiótica estuviera encuadrada en un marco fundamentalmente lingüístico y a cargo de docentes de los áreas de linguística y literatura de las universidades uruguayas.

En esta primera etapa de presentación en sociedad de la disciplina, los artículos se dedicaron a difundir líneas teóricas tributarias de la semiología europea. Desde los principales problemas formulados por el estructuralismo y el postestructuralismo a la presentación de autores como Saussure, Hjelmslev o Benveniste, estos primeros trabajos 
semióticos en Uruguay eligieron a los lenguajes naturales y a la literatura como objetos desencadenantes de los análisis (Argañaraz, 1985a, 1985b, 1987; Lavandeira, 1986; Salomón, 1985).

El teatro fue otro de los objetos problematizados en esta primera época. A partir de un enfoque presentado como postestructuralista, los análisis se concentraron en la estructura del lenguaje teatral y su relación necesaria con los signos lingüísticos (Burgueño \& Viroga, 1988d, 1988e).

La opción por la orientación europea incluyó la distinción entre semiología y semiótica, pero en tanto términos sinónimos: «La semiótica o semiología [es la] ciencia o teoría general de los signos» (Argañaraz, 1985b: 7) (subrayado mío). El terreno todavía difuso de la disciplina habilitó a que se manejaran ambas nominaciones indistintamente, aunque la inclinación analítica de Relaciones optara por un marco teórico de raíz estructuralista.

Alternativamente, otra publicación también independiente del aparato universitario comenzó a hacerse cargo de la difusión semiológica en forma exclusiva. De corte netamente postestructuralista, Maldoror, revista de la ciudad de Montevideo ubicó su producción en el análisis de lo literario, pero abriendo el juego a la problematización cinematográfica desde los aportes de la teoría de la recepción de Jauss y la narratología de Genette.

La misma orientación se ha reiterado en la obra posterior de Lisa Block de Behar, integrante del consejo de redacción de dicha revista y cuya producción individual podría considerarse como emblemática de la semiología postestructuralista uruguaya, donde el interés fundamental ha estado en el análisis de objetos literarios y cinematográficos integrantes del canon belle-letrístico como es el caso de la literatura de Jorge Luis Borges, o el cine de Woody Allen y de Wim Wenders entre otros (Block de Behar, 1990, 1994; Block de Behar \& Rigoli, 1997).

\section{EL MODELO GREIMASIANO: DISCURSO Y PODER}

Al tratarse de una publicación ecléctica, la revista Relaciones habilitó la presencia de otras líneas de abordaje semiótico, como fue el caso de la propuesta de la Escuela de Paris y el modelo de Greimas. 
Michel Boulet, francés radicado en Uruguay, ha sido quien hasta la fecha ha contribuido en forma más regular a la difusión del pensamiento greimasiano en el país. Adscribiendo a la formulación de la semiótica en tanto disciplina cuyo «... objeto [es] el conjunto de discursos que intervienen en la constitución y/o la transformación de lo social» (Boulet, 1992: 9), este autor ha concretado a lo largo de los años una producción analítica basada en la gramática narrativa y eligiendo como objeto de análisis casi hegemónico al discurso político (Boulet, 1987, 1989c, 1989e, 1992).

\section{EL SEMANÁLISIS DE JULIA KRISTEVA: UN LUGAR PARA LO FEMENINO}

Otra salida al proyecto estructuralista ortodoxo ha sido la definida por Hilia Moreira en su postura analítica: «... Al ocuparse del signo, de su producción, de su ideología, se hace necesario prestar particular atención al sujeto que lo emite. De ahí las frecuentes referencias al terreno del psicoanálisis. $O$, tal vez, más que de una semiótica, habría que hablar, como dice Julia Kristeva (semióloga y psicoanalista) de una semanálisis» (Moreira, 1992a: 10).

Esta autora ha elegido, como uno de sus espacios de análisis privilegiados, el objeto televisivo latinoamericano por excelencia: el teleteatro. Sus aproximaciones se han caracterizado por el análisis de los mecanismos narrativos del género y el establecimiento de relaciones intertextuales entre diversos discursos occidentales a partir de la propuesta poética de Aristóteles, el pensamiento psicoanalítico de Lacan y los planteos feministas de Tania Modleski (Moreira, 1987a, 1987d, 1988b, 1989b, 1995a). Ha integrado el plano de la recepción de sus estudios considerando la incidencia potencialmente educativa del género en los países de América Latina y concretamente Uruguay (Moreira, 1989c, 1991b, 1992f; Moreira \& Etchevarren, 1988, 1989; Moreira \& Sánchez, 1989, 1990).

Intentando circunscribirse en el discurso amoroso, la autora ha estudiado las diferentes manifestaciones de uno de los principales arquetipos femeninos de occidente: la figura amada. Estableciendo como lugar de partida la fascinación que el punto de vista masculino-creador de sentido ha experimentado por lo femenino-creado, Moreira ha 
mirado semanalíticamente las figuras de representación del relacionamiento amoroso a partir del análisis de textos literarios y cinematográficos que van desde Juan Carlos Onetti y Manuel Puig a Alfred Hitchcock y Carlos Saura (Moreira, 1992a).

Privilegiando el lugar de lo femenino, ha extendido su mirada a la topografía semiótica de la corporalidad (Moreira, 1991a, 1992b, 1992c, 1992d, 1993b, 1993c) y, especialmente, a las manifestaciones del cuerpo de la mujer que la cultura ha significado como abyectas e irrepresentables. Centrándose en el análisis de la menstruación representada en la literatura, la publicidad, el teleteatro y las comedias de situación televisivas, la autora ha intentado sistematizar una poética de lo vergonzante. Según sus propios términos, «... [la semiótica de la ignominia pretende estudiar] algunos de los signos que el cuerpo femenino emite, inevitable y cotidianamente. $O$ aquellos otros que, según la tradición, suele dejar a su paso. Son signos más o menos triviales. Pero la doxa los tacha de "ignominios": privados de nombre por considerarse vergonzantes. Es tarea de la semiótica traer a la palabra y buscar los significados de toda productividad humana, premeditada o involuntaria, palpable ofantasiosa» (Moreira, 1994a: 22).

\section{LA SOCIOSEMIÓTICA: VIDA COTIDIANA Y MEDIOS MASIVOS}

Debido a un contexto histórico particular que exigía una consideración del sentido en términos no solamente estructurales, la primera revisión radical de la línea semiológica uruguaya le correspondió a los modelos sociosemióticos de análisis. La culminación del gobierno autoritario de las décadas del setenta y parte de los ochenta, exigió una aproximación a los fenómenos del país que estuviera necesariamente abierta al contexto en que estos estaban inscritos:

No se nos ocurre mejor descripción para el trabajo del linvestigador en semiótica] (...) sobre las prácticas sociales que ese gesto de augur demarcando zonas de interés en el firmamento del gigantesco texto construido por la producción de los discursos sociales (Andacht, 1987a: 9).

Desde ese interés focalizado en la noción de discurso-semiosis social, estas nuevas aproximaciones habilitaron la apertura hacia dos 
universos de sentido que la semiología en Uruguay había considerado no relevantes para el análisis: la vida cotidiana y los medios masivos.

Reconstruyendo un marco teórico integrado por los aportes de la sociofenomenología norteamericana, la microsociología de Goffman, la metacomunicación de Bateson y la retórica-verosimil de Aristóteles, la nueva perspectiva redefinió el estatuto del ejercicio semiótico en la academia uruguaya al establecer como «... operación semiótica por excelencia: volver explícito lo implícito" (Andacht, 1987a: 16).

Entre los nuevos objetos de análisis aparecieron como temas la reflexión en torno a la problemática del nombre y los desaparecidos políticos (Andacht, 1985), la redefinición del discurso educativo en términos democráticos (Andacht, 1986a), la consideración de los aspectos relevantes en la producción de noticias (Álvarez, 1988), la espectacularización de los programas de la nueva televisión (Andacht, 1986d), la emergencia de fenómenos culturales redefinidores de paradigmas más tradicionales como el teatro de vanguardia (Andacht, 1987e), el mundo de la publicidad (Perroni, 1994).

La sociosemiótica en Uruguay prestó especial atención a los signos con que los microrelatos evidenciaban los macro-ejes de sentido de una sociedad que estaba en proceso de cambio. La lógica de análisis fue justamente esa consideración de lo social como lugar dinámico y en constante juego con el universo de los espacios mínimos: «Propongo ver los signos en acción. En una acción que respeta pero a la vez desborda las regiones que esos mismos signos se encargan de definir.(...) Historia de las mentalidades, de las ideologías, o de las técnicas, todas ellas pueden beneficiarse de una atenta y sistemática consideración de la semiosis social, es decir, de la interacción cotidiana como trasiego de signos» (Andacht, 1989a: 8).

\section{CHARLES S. PEIRCE: LOS MITOS Y LAS PASIONES URUGUAYAS}

Como oposición radical al proyecto semiológico, la propuesta semiótica de Charles S. Peirce apareció en algunos casos presentada por autores cuyo interés radicaba en la difusión nominal del norteamericano sin espacios concretos de análisis. Se dio el caso en algunos artículos aislados donde se recorría históricamente y a grandes rasgos 
la perspectiva fenomenológica (Argañaraz \& Tani, 1987; Tani 1984; Tani et alt, 1991).

El uruguayo que ha sistematizado en forma más regular la interpretación de los fenómenos de sentido sociales desde la lógica peirciana ha sido Fernando Andacht. Presentando la propuesta y reflexionando en torno a la abducción y sus relaciones con los planteos del juego en Winnicott o la interacción en Goffman (Andacht, 1990b, 1992b, 1993b), o a la relación de la faneroscopía de Peirce con el psiconálisis (Andacht, 1990c, 1994; Andacht \& Gil, 1994), estas publicaciones tienen en común la ejecución de la operatividad que la propia semiótica ha definido para la lógica triádica frente a la concepción binaria de la semiología.

En un intento por desuniversalizar la tradición teórica de la semiología en Uruguay, Andacht ha apoyado su trabajo interpretativo del imaginario uruguayo desde la perspectiva de la semiosis social: «Mi hipótesis es simple, (...) persigue la búsqueda minuciosa del trayecto cotidiano de la mirada comunitaria (...) La televisión, algunas imágenes públicas (...) configuran el derrotero del sentido común. Estas imágenes fuertes, no fáciles de olvidar trazan la ruta a seguir por ese saber construido colectivamente y sometido a plebiscito cotidiano que conocemos como la opinión pública» (Andacht, 1992a: 14).

Oponiendo en sus textos aquellas zonas de la cultura que aparecen estigmatizadas por la ley y aquéllas que se le oponen, su nominación de mesocracia para entender las lógicas de adjudicación de sentido público y privado, funcionó institucionalmente como legitimador de la propia semiótica en Uruguay cuando su libro Signos reales del Uruguay imaginario obtuvo el premio «Bartolomé Hidalgo» en 1994 como mejor texto de ciencias sociales publicado en el país.

Centrado en el análisis de las fronteras semióticas de lo uruguayo, Andacht ha relevado el imaginario de Cornelius Castoriadis y la transvaluación mítica de James J. Liszka para trazar un mapa de lo pensable, lo decible y lo deseable para esta zona del Río de la Plata. Desde este margen, el autor ha definido su lugar semiótico en la visualización del qué y el cómo de los lugares míticos que explican e identifican a lo uruguayo, en los siguientes términos: «Mi análisis sociosemiótico de la sociedad uruguaya en la última década se basa en esta premisa: los mitos, o dispositivos de verosimilitud, son el freno universal autoimpuesto por el hombre como medio de acotar el rico pero angustiante universo ilimitado de aspectos o potencialidades del signo, al 
que se enfrenta cualquier comunidad humana para referirse a algo» (Andacht, 1992a: 152).

Los lugares que se resisten a la legalidad necesaria que promueven los mitos han sido trabajados en su análisis de las pasiones, «... el lado oscuro, el menos presentable y más elocuente de esta región del mundo» (Andacht, 1996a: 11). Figuras del fútbol, presentadores de informativos, periodistas famosos y actores conocidos han aparecido en esta propuesta como objetos desencadenantes de la pasión-cualidad-estética que para presentarse como tal remite inevitablemente al peso legitimador de la ley.

Analizando estas formas de la alteridad, el autor ha habilitado una concepción de lo uruguayo que necesita y va más allá de la normalidad mesócrata, postulando que toda vida cotidiana es una triproducción entre pasiones, razones y cuerpos.

\section{Revelamiento bibliográfico de publicaciones}

ÁlVAREZ, LuCIANo (1988). Los héroes de las siete y media. Los noticieros en la televisión uruguaya. Montevideo: Centro Latinoamericano de Economía Humana.

ANDACHT, FERNANDO (1985). «El "doble exilio" de la palabra». Revista Relaciones 19, diciembre (Montevideo), 6-8.

- (1986a). «La educación, ¿debe imponer una ética?». Revista Relaciones 24, mayo (Montevideo), 7-9.

- (1986b). «En el teatro y en la vida: el encuadre». Revista Relaciones 25, junio (Montevideo), 4-6.

- (1986c). «El nombre propio». Revista Relaciones 29, octubre (Montevideo), 6-8.

- (1986d). «El Castillo de la Suerte: televisión pura». Revista Relaciones 31, diciembre (Montevideo), 3.

- (1987a). El paisaje de los signos. Semiótica y sociedad uruguaya contemporánea. Montevideo: Montesexto.

- (1987b). «Todos los caminos llevan al signo». Revista Relaciones 32/33, enero/febrero (Montevideo), 19-21.

- (1987c). «Imagen y palabra». Revista Relaciones 34, marzo (Montevideo), 7-8.

- (1987d). «¡Metz, cámara y acción!». Revista Relaciones 39, agosto (Montevideo), 9-11.

- (1987e). «Auténticamente falso». Revista Relaciones 40, setiembre (Montevideo), 2. 
- (1988a). «Saber y poder». Revista Relaciones 44/45, enero/febrero (Montevideo), 17.

- (1988b). «Representación y teatro». Revista Relaciones 47, abril (Montevideo), 10-11.

- (1988c). «La función del teatro de vanguardia». Revista Relaciones 50, julio (Montevideo), 7-8.

- (1989a). De signos y desbordes. Semiótica y sociedad. Montevideo: Montesexto.

- (1989b). «La insoportable levedad del signo». Revista Relaciones 62, julio (Montevideo), 14-15.

- (1989c). «Populismo: un discurso negado». Revista Relaciones 63, agosto (Montevideo), 22-24.

- (1989d). «Desencanto y herejía en política». Revista Relaciones 66, noviembre (Montevideo), 24-25.

- (1990a). «El oscuro objeto del diseño». Revista Relaciones 68/69, enero/febrero (Montevideo), 7.

- (1990b). «El espectáculo del poder». Revista Relaciones 70, marzo (Montevideo), 21-23.

- (1990b). «Faneroscopía, pragmática y abducción». Revista Relaciones 74, julio (Montevideo), 22-25.

- (1990c). «Las malas palabras en cuestión: la Ley, su Otro y el Desliz». Revista Relaciones 75, agosto (Montevideo), 5-7.

- (1991). «Lugares comunes desde ningún lugar». Revista Relaciones 91, diciembre (Montevideo), 21-24.

- (1992a). Signos reales del Uruguay imaginario (Montevideo, Trilce).

- (1992b). «Semiosis microsocial: los signos de Erving Goffman». Revista Relaciones 100, Separata 3, setiembre (Montevideo), 2730.

- (1993a). Entre signos de asombro. Antimanual para iniciarse a la semiótica. Montevideo: Trilce.

- (1993b). «Semiosis, pasión y muerte del self romántico». Deslindes 2/3 (Montevideo, Biblioteca Nacional), 299-319.

- (1994). «La importancia de la Ley: Caín y Abel». En Daniel Gil (comp.), Antiguos crímenes. Edipo - Narciso - Caín, 135-151. Montevideo: Trilce.

- (1995a). «¿Somos grises?». Revista Relaciones 130, marzo (Montevideo), 21-22.

- (1995b). «Discurso electoral. Dos transgresores». Revista Relaciones 133, junio (Montevideo), 30-31.

- (1996a). Paisaje de pasiones. Pequeño tratado de las pasiones en mesocracia. Montevideo: Fin de Siglo.

- (1996b). «Discurso político local: cosas del querer». Revista Relaciones 151, diciembre (Montevideo), 8-11.

ANDACHT, F. \& GIL, DANIEL (1994). «Más allá del principio de placer: la abducción, un efecto de lo real». En Ricardo Bernardi et alii (eds.), 
Interpretar, conocer, crear... Diálogo desde la in(ter)disciplina, 251-271. Montevideo: Trilce.

ANDACHT, F. et alii (1987). «El homo semióticus». Revista Relaciones 37, junio (Montevideo), 17.

ARAúJo, ANA MARÍA (1988). «Contrapunto entre lenguaje y filosofía.

Inocencia sospechosa». Revista Relaciones 51, agosto, 18.

ARGAÑARAZ, Nicteroy N (1985a). «La ironía desde la perspectiva pragmática». Revista Relaciones 11, abril (Montevideo), 16-17.

- (1985b). «Contribución de Benveniste a la semiótica literaria». Revista Relaciones 18, noviembre (Montevideo), 7-9.

- (1986). «Intertextualidad. Traducción, transcreación». Revista Relaciones 31, diciembre (Montevideo), 8-9.

- (1987). «Semiología literaria: influencia de Hjelmslev». Revista Relaciones 40, setiembre (Montevideo), 7-9.

Argañaraz, N.N. \& Tani, Ruben (1987). «La semiótica de Peirce». Revista

Relaciones 34, marzo (Montevideo), 9-11.

AROCENA, FeliPE (1989). «El problema del sentido y el estructuralismo». Revista Relaciones 64, setiembre, 14-16.

- (1991). «La construcción del significado en la vida cotidiana». Revista Relaciones 82, marzo, pp. 8-10.

BERVEJLLO, FEDERICO et alii (1985). «Comunicación, significado y arquitectura». Revista Relaciones 14, julio, 6-7.

BLOCK DE BEHAR, LISA (1973). El lenguaje de la publicidad. Buenos Aires: Siglo XXI.

- (1980). «La comunicación cinematográfica». Maldoror. Revista de la ciudad de Montevideo 15, noviembre, 47-49.

- (1984). Una retórica del silencio: funciones del lector y procedimientos de la lectura literaria. México: Siglo XXI Editores.

- (1985a). «Introducción». Maldoror. Revista de la ciudad de Montevideo 19: Experiencia estética y teoría de la recepción literaria, s/n, 9-16.

- (1985b). «A manera de prólogo». Maldoror. Revista de la ciudad de Montevideo 20: El Texto según Gérard Genette, s/n, 15-30.

- (1987). Al margen de Borges. Buenos Aires: Siglo XXI.

- (1990). Dos medios entre dos medios. Sobre la representación y sus dualidades. Buenos Aires: Siglo XXI.

- (1994). Una palabra propiamente dicha. Buenos Aires: Siglo XXI.

BLOCK DE BEHAR, L. \& RIGOLI, ANDREA (coord) (1997). Escrito sobre el cine Montevideo: Ciencias de la Comunicación-Comisión Sectorial de Investigación Científica-Universidad de la República.

Boulet, Michel (1986a). «Semiótica: la Escuela de Paris». Revista Relaciones 29, octubre (Montevideo), 10-12.

- (1986b). «Lectura del Libro Primero». Revista Relaciones 31, diciembre, 14-15.

- (1987). «Discurso político: poder y verdad». Revista Relaciones 35, abril, 6-8. 
- (1989a). «Hacia una definición de la semiótica». Revista Relaciones 61, junio, 9-10.

- (1989b). «Sobre el discurso político». Revista Relaciones 63, agosto, 20-22.

- (1989c). «La imagen de un líder». Revista Relaciones 64, setiembre (Montevideo), 23-24.

- (1989d). «Psicoanálisis y semiótica». Revista Relaciones 64, setiembre, 12.

- (1989e). «Campañas políticas por televisión». Revista Relaciones 65, octubre, 23-24.

- (1990). «¿Cambian los teleteatros?». Revista Relaciones 71, abril, 2021.

- (1992). Uruguay ¿país en transición? Estudios semióticos. Montevideo: Ediciones de Juan Darién.

BuRgueÑo, MARÍA Esther (1997). «En la encrucijada del teatro "El Plauto"». Revista Relaciones 152/153, enero/febrero, 27-28.

BURGUEÑO, M.E. \& VIROGA, SILVIA (1988a). «Comunicación literaria, espacio de libertad». Revista Relaciones 48, mayo, 14-15.

- (1988b). «La (a)ventura del texto». Revista Relaciones 58, marzo, 1617.

- (1988c). «Los umbrales del texto». Revista Relaciones 61, junio, 2122.

- (1988d). «La comunicación en el teatro». Revista Relaciones 66, noviembre, 12-13.

- (1988e). «El zoo de los signos». Revista Relaciones 72, mayo, 10-11.

- (1991). «Personaje, no persona». Revista Relaciones 84, mayo, 1920).

DotTA, AMANECER (1994). «La paradoja del actor semiótico». Revista Relaciones 94 (Montevideo), 22-25.

ETCHEVARREN, PERLA (1988). «El video educativo: ¿boom o bluff?». Revista Relaciones 55, diciembre, 19-20.

LAVANDEIRA, MAGALY (1986). «Semiótica narrativa». Revista Relaciones 23, abril, 15-17.

Moreira, HILIA (1987a). «"Brillante": un teleteatro brasileño entre la tradición y el experimento». Revista Relaciones 32/33, enero/febrero, 10-11.

- (1987b). «Diciendo sin decir. Análisis del lenguaje no verbal en la vida cotidiana del Uruguay y otros países». Revista Relaciones 35, abril, 17-19.

- (1987c). «La pornografía: figura de la renuncia». Revista Relaciones 37, junio, 9-10.

- (1987d). «El tiempo en las seriales». Revista Relaciones 41, octubre, 8.

- (1987e). «Preguntas a Umberto Eco». Revista Relaciones 43, diciembre, 15.

- (1988a). «Literatura y minorías. Entrevista con Dominique Fernández». Revista Relaciones 46, marzo, 2-3. 
- (1988b). «El teleteatro como máscara». Revista Relaciones 55, diciembre, 6- 8 .

- (1989a). «Eladio Linacero o el mito de Narciso». En Rómulo Cosse (ed, Juan Carlos Onetti: papeles críticos, 71-92. Montevideo: Linardi \& Risso.

- (1989b). «Traslados y adaptaciones». Revista Relaciones 58, marzo, 16.

- (1989c). «Televisión, niños y familia en América del Sur». Revista Relaciones 64, setiembre, 28.

- (1990a). «¿Puede el cine representar la pasión?: El pensamiento de Julia Kristeva». Revista Relaciones 71, abril, 20-21.

- (1990b). «Entre el cine y la fotografía: el teleteatro brasileño». Revista Relaciones 73, junio, 20-22.

- (1991a). «Semiótica de la ropa interior». Revista Relaciones 80/81, enero/febrero, 4-7.

- (1991b). «Televisión, educación y marginalidad». Revista Relaciones 85, junio, 16-17.

- (1992a). Mujer, deseo y comunicación. Imágenes femeninas en la literatura y el cine. Montevideo: Linardi \& Risso.

- (1992b). «Curvas, peinados, perfumes. Para una semiotica de la corporalidad sexuada». Revista Relaciones 92/93, enero, 5-9.

- (1992c). «Desnudez femenina: del satanismo a las bodas». Brecha, marzo (Montevideo), 7.

- (1992d). «Largos cabellos de libertad». Brecha, abril, 7.

- (1992e). «Cotidianeidad, tecnología, erotismo». Temas de Comunicación 1, agosto (Montevideo, Revista de la Licenciatura en Ciencias de la Comunicación de la Universidad de la República), 50-55.

- (1992f). «El potencial educativo del teleteatro». Temas de Comunicación 1, agosto (Montevideo, Revista de la Licenciatura en Ciencias de la Comunicación de la Universidad de la República), 59-67.

- (1992g). «La mirada, haz de signos». Teorema. Revista de comunicación social y desarrollo 5, agosto (Montevideo), 5-9.

- (1992h). «Shelley y Mary. Ecólogos, feministas y pacifistas hace 200 años». Revista Relaciones 99, Separata 2, agosto, 10-12.

- (1993a). «Semiótica de la menstruación. El manar misterioso». Brecha, enero, 7.

- (1993b). «Semiótica y corporalidad. Cabellos del buen amor». Revista Relaciones 103, enero/febrero, 12-13.

- (1993c). «Semiótica y corporalidad. La leche de las galaxias». Brecha, marzo, 7.

- (1993d). «Semiótica de la ignominia». Brecha, junio, 7.

- (1994a). Cuerpo de mujer. Reflexión sobre lo vergonzante. Montevideo: Trilce.

- (1994b). «Medicina, menopausia y medios de comunicación». En José Pedro Barrán (comp.), Medicina y sociedad, 175-208. Montevideo: Editorial Nordam. 
- (1994c). «Cuernos, signo de Dios». Revista Relaciones 119, abril, 1011.

- (1995a). «Teleteatro y academia». En Joaquín Rodríguez Nebot \& José Portillo (comp.), Medios de comunicación y vida cotidiana, 155198. Montevideo: Multiplicidades.

- (1995b). «La inmundicia: un espacio femenino». Cuadernos de Marcha 148 , setiembre/octubre, 7 .

- (1997). «El arte de Eduardo Vernazza: una visión semiótica». Revista Relaciones 163, diciembre, 21-23.

Moreira, H. \& Basso, Eleonora (1990). «Carmen, bruja y madre. Semiótica de una incomunicación». Revista Relaciones 77, octubre, 24-25.

Moreira, H. \& Etchevarren, Perla (1988). «Especificidad del lenguaje audiovisual». Revista Relaciones 53, octubre, 19-20.

- (1989). «Televisión en las aulas uruguayas». Revista Relaciones 61, junio, 14-16.

MoReIRA, H. \& SÁNCHEZ, MATLDE (1989). «Literatura y medios masivos». Revista Relaciones 66, noviembre, 3.

- (1990). «Poética para una educación recreativa». Revista Relaciones 76, setiembre, 18-19.

NaVATta, LaURa \& Serrano, Victor (1994). «Maten a Grecia Colmenares. Los límites de la estética tradicional». Revista Relaciones 96, mayo, 14-15.

Perroni, Nani (1994). «Fido Dido y la cibernética». Revista Relaciones 102, noviembre, 11-13.

- (1995). «El "Eco" de la buena onda». Revista Relaciones 136, setiembre, 19-20.

Perroni, Nani \& Calichio, Leo (1994). « ¿Culpable! Hasta que un boleto pruebe lo contrario». Revista Relaciones 98, julio, 4-6.

Rozas, Sergio (1995). «Las transparencia del significado». Revista Relaciones 138 , noviembre, 5-7.

- (1996). «Palabras: usos y significado. El lenguaje como problema». Revista Relaciones 144, mayo, 12-13.

Salamanovich, David-Elliot (1995). «¿Cómo habla una sociedad? Vestimenta y lenguaje». Revista Relaciones 134, julio, 25-26.

SALOMÓN, MÓNICA (1985). «Pragmática: estructuralismo y después...». Revista Relaciones 15, agosto, 7-8.

SILVERSTEIN, IANAI (1992). «Shelley, antecesor de la semiótica». Revista Relaciones 100, Separata 2, agosto, 13.

TANI, RuBÉn (1979). «Los grados de analogía. Semiología y semiótica». Revista Prometeo I, 1, s/f (Montevideo, Facultad de Humanidades y Ciencias, 93-116.

- (1984a). Pretextos: o cómo hacer un libro de poemas. Montevideo: Facultad de Humanidades y Ciencias.

- (1984b). «La semiótica fenomenológica: de Hegel a Peirce». Revista de la Facultad de Humanidades y Ciencias, vol. $1, \mathrm{n} .{ }^{\circ} 2$, noviembre (Montevideo), 9-16. 
- (1986). «Función poética en el discurso presidencial». la Revista Relaciones 30, noviembre.

TANI, RuBÉn et alt (1991). Discurso, semiótica, sociedad. Problemas de las disciplinas sociales después del estructuralismo. Montevideo: Ceadu.

VISCARDI, RICARDO (1986). «Entre el discurso y su objeto». Revista Relaciones 26 , julio, pp. 7-8. 